ISSN 2413-0877 Volume 1 (2015)

The 1st International Symposium on Aquatic Product Processing 2013

\title{
DEVELOPMENT OF PORTABLE SYSTEM FOR MUSCLE TWITCH EXPERIMENT MEASUREMENT OF MUSCLE CONTRACTION TIME
}

\author{
Mochammad Riyanto',2)*, Takafumi Arimoto') \\ Graduate School of Applied Marine Biosciences, Tokyo University \\ of Marine Science and Technology \\ Faculty of Fisheries and Marine Sciences, Bogor Agricultural University \\ *e-mail: mh_ryn@yahoo.com
}

\begin{abstract}
The muscle contraction time of fish can be the good index for swimming capability to estimate the maximum swimming speed, by defining the maximum tail beating performance. The muscle contraction time of jack mackerel, Thachurus japonicus (18.0-19.4 cm of fork length (FL), $\mathrm{n}=$ 15) was measured with newly developed portable systemand compared with the conventional setup with the electric stimulation pulse from generator and battery system. The muscle contraction profile was not different among each measurementeven with the different pulse pattern of electric stimulation between portable and conventional setup. The shortest recording of muscle contraction time with the portable system was $22.6 \pm 2.1 \mathrm{~ms}$, not different to the conventional system as $24.3 \pm 1.9 \mathrm{~ms}$ with the generator and $24.2 \pm 2.0 \mathrm{mswith}$ the battery system. Time duration and the pulse pattern of the electric stimulus do not affect the muscle contraction time. The portable system can be used to measure the muscle contraction time of fish for the field experiment and onboard the fishing boat without alternating current (AC) electricity supply.
\end{abstract}

Keywords: Muscle contraction time, jack mackerel, portable system, electric stimulus, muscle twitch experiment.

\section{INTRODUCTION}

Muscle twitch experiments have been developed for measuring the muscle contraction properties of the fish in order to estimate the maximum tail beat frequency and the maximum swimming speed (Wardle 1975). Original setup of muscle twitch experiment was developed by Wardle (1975), as the experiment apparatus includedan AC electric generator for the stimulus pulse, electric stimulator and a two-channel storage oscilloscope.Further studies were conducted by using similar system to measure muscle contraction time and evaluating the maximum swimming speed of skipjack tuna (Katsuwonus pelamis) (Brill and Dizon 1979), cod (Gadus morhua), cuckoo ray (Raja naevus) (Johnston 1980), mackerel (Scomber scombrus) (He 1986), jack mackerel (Trachurus japonicus) (Xu1989) and walleye pollock (Theragra chalcogramma) (Arimoto1990). Contemporary study was conducted to determine the temperature effect on the muscle contraction time and the swimming performance of haddock (Melanogrammus aeglefinus)(Ozbilgin2002), sandflathead(Platycephalus bassensis) (Yanase 2007), red mullet (Mullus berbatus) and sea bream (Diplodus annularis) (Ozbilgin 2011).The characteristic of muscle contraction profile recorded by alternating current (AC) electric stimulator was reported by Xu (1989), Arimoto et al. (1990), and Amornpiyakrit (2003). 
The portable system for muscle twitch experiment was firstly developed by Wardle et al. to measure muscle contraction time of giant bluefin tuna (1989). The main apparatus of portable system consisted of specially designed transducer, a portable battery-operated unit containing the stimulator circuit and a computer board. The portable system in the previous study by Wardle (1989), the muscle contraction timewas directly shown as the digital data, not as the muscle contraction profile.

In order to develop the modern device with a data recorder system, the problem is the electric stimulator. The conventional setup of an electric stimulator on the portable system is generated by $A C$ electricity supply, which is not available for the field experimentonboarding small fishing boat.As a way for resolvingthis problem, we have changed the electric stimulator with the battery system and compared the muscle contraction and electric stimulation pulse profiles between the conventional and the new portable system.

\section{MATERIAL AND METHODS}

Jack mackerel (Trachurus japonicus) (18.0- $19.4 \mathrm{~cm}$ of fork length FL, $n=15)$ was used to determine the muscle contraction time using aportable and conventional system. The fish were obtained from a keeping cage in Numazu Bay, Shizuoka, Japan. Fish were kept in a rectangular fiber glass tank $(200 \mathrm{~cm}$ long; $90 \mathrm{~cm}$ wide; $100 \mathrm{~cm}$ deep), where sufficient aeration was provided. All the fish were kept for at least 10 days prior to the experiment. Details experimental fish were described in the previous paper by Riyanto et al. (2013).

A maximum of 5 positions along the body were tested from each individual of fish. The selected position of the fish body was pierced with two needles of $7 \mathrm{~mm}$ distance attached to the specially designed muscle twitch transducer. A $1.5 \mathrm{~V}$ stimulation pulse was delivered via needles of the transducer to the muscle from two units of battery 1 sized $1.5 \mathrm{~V}$ connected in the parallel, for the time duration of $20-100 \mathrm{~ms}$ by manual switching-on and -off. The muscle responded the stimulation pulse by contracting and bending acrylic plate of the transducer, which changed the resistance of the attached strain gauge (KYOWA, Type KFWS-2N-120$\mathrm{Clz} 11 \mathrm{L3M} 2 \mathrm{R}$ ). This resistance was recorded by a portable strain data recording device (EDS400A) powered by battery system (ESB-04A), for connecting to the computer through DCS100A software. The elapsed time from delivery of the pulse to the peak of resistance is defined as the muscle contraction time (Wardle 1975). The experimental apparatus setup of a portable system is shown Figure 1. 


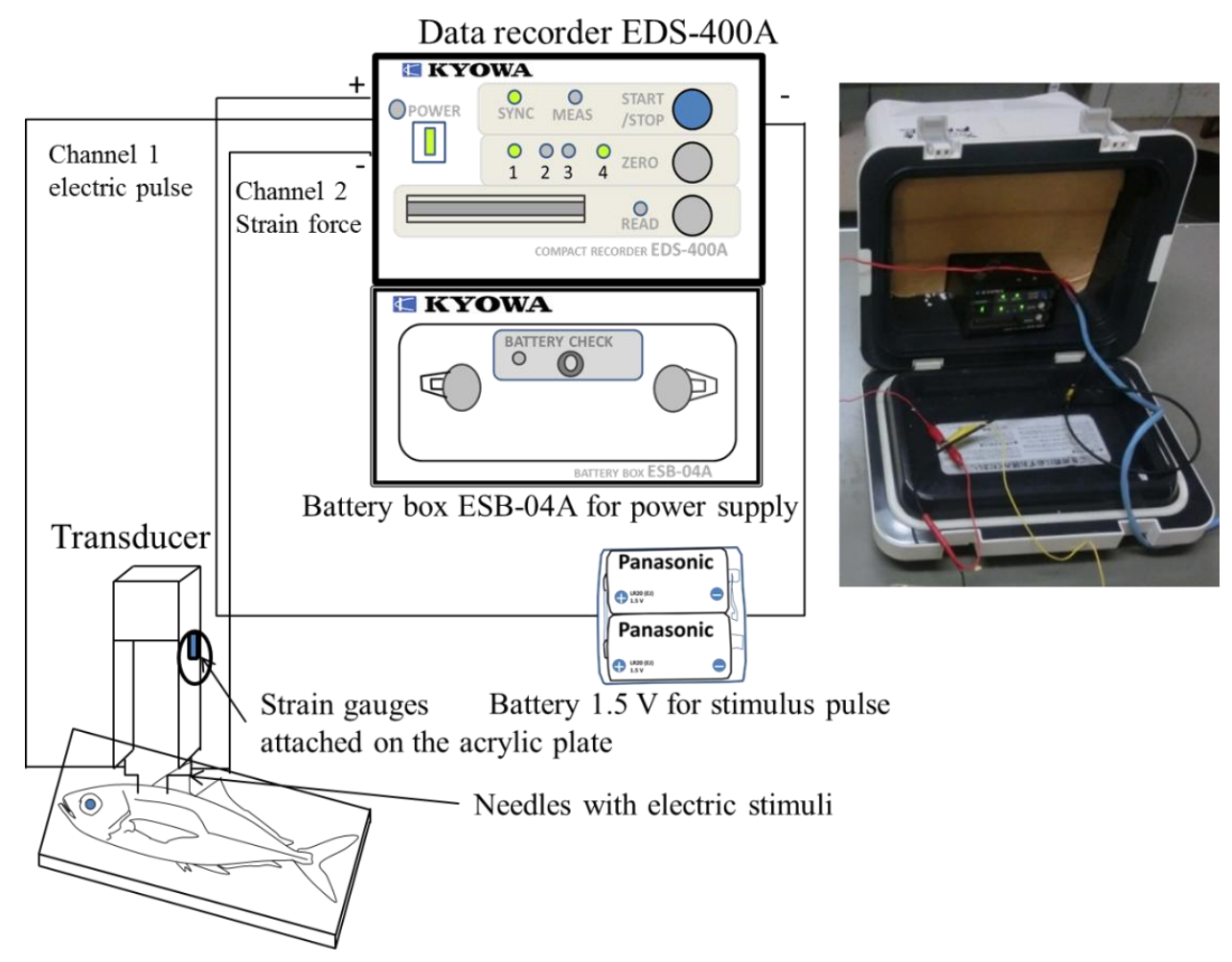

Figure. 1 Experimental apparatus setup of portable battery system

The conventional setup with $A C$ powered unit is shown in Fig 2. The electric pulse generator (Nihon-Kohden, SEN-2201) can set the stimulus pulse with the range of voltage amplitude as $0.1-100 \mathrm{~V}$, for the time duration $0.1-3 \mathrm{~ms}$ pattern. The standard protocol of stimulation pulse as $2 \mathrm{~V}, 2 \mathrm{~ms}$ was delivered from an electric pulse generator to the muscle via needles of the transducer, as the same setup in the previous studies by Xu (1989), Arimoto et al. (1991) and Riyanto et al. (2013). For confirming the amplitude effect of the stimulus pulse, $5 \mathrm{~V}$ pulse was also examined for the same specimen with the standard $2 \mathrm{~V}$ pulse. The strain forceloaded on the strain gauge was transformed to the electric resistance by a strainamplifier (KYOWA, DPM-1 102) and was displayed on an oscilloscope (Iwatsu Electric, DS5102). The strain amplifier was set at a sensitivity of $100-1000 \mathrm{mV}$ of the strain with the low/high filter at the band width of $100 \mathrm{~Hz}$.

The conventional set-up with the battery system was used to confirming the validity of the battery system for generating the electric stimulus pulse to measure muscle contraction time. Two units of the battery 1 sized $1.5 \mathrm{~V}$ set in parallel was used for generating stimulus pulse, by connecting to the bio-amplifier and needles of the muscle transducer. The conventional set-up with the battery system is shown in Figure 3 . 


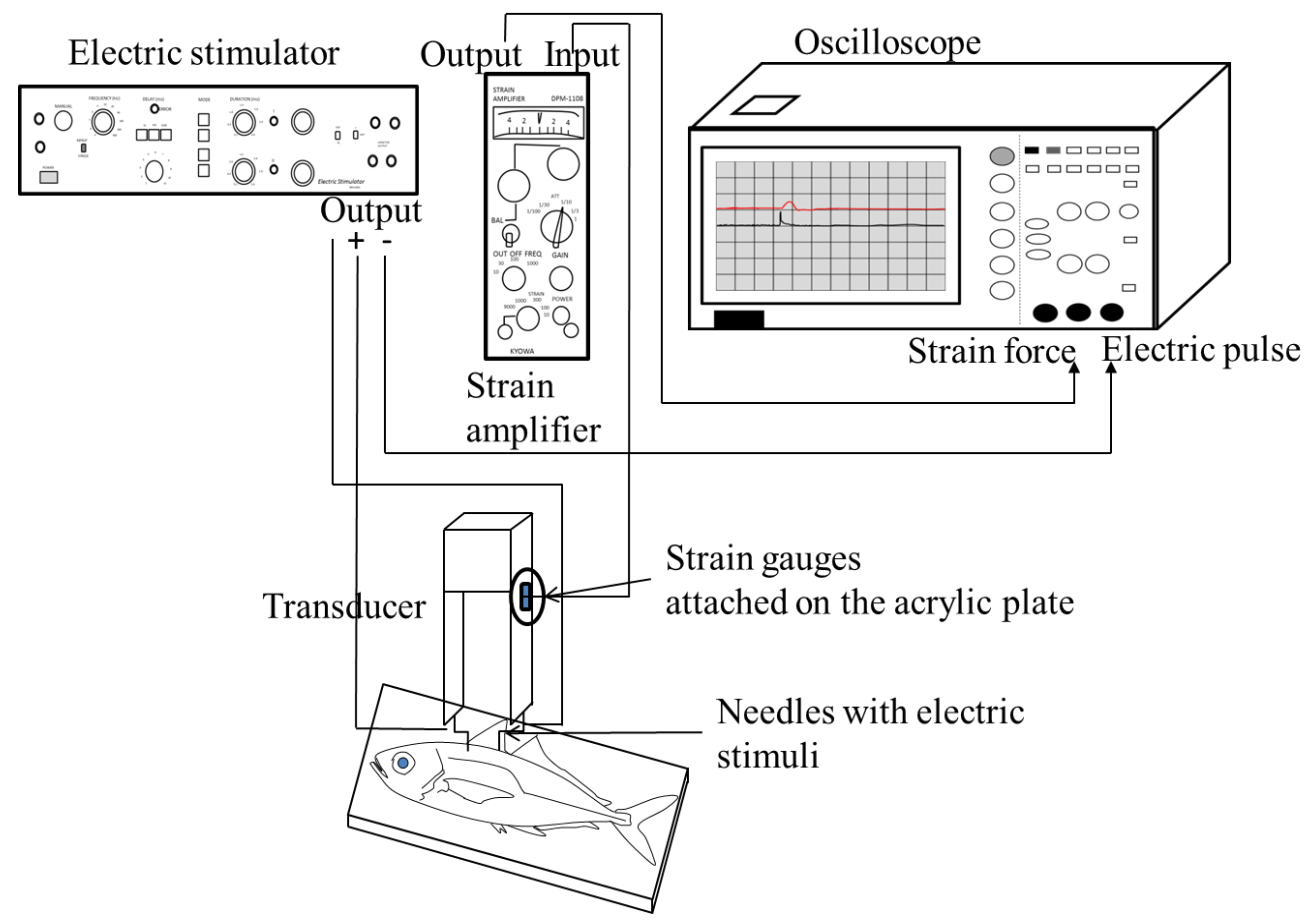

Figure. 2 Experimental apparatus setup of electric stimulator with the pulse generator

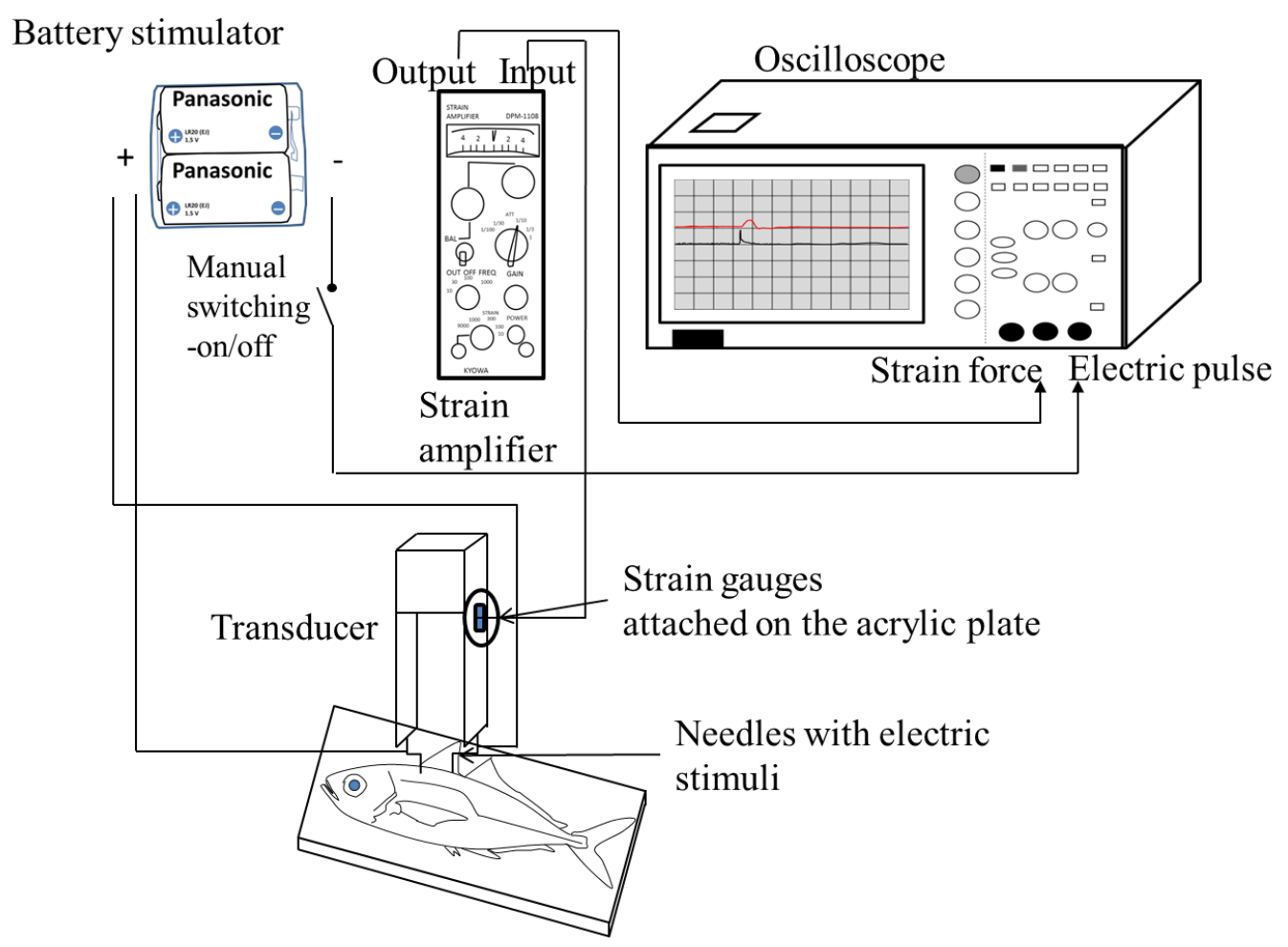

Figure. 3 Experimental apparatus setup of electric stimulator with the battery

\section{RESULTS AND DISCUSSIONS}

An example of the muscle contraction profile from jack mackerel by a portable system was shown in Fig. 4. Muscle contraction time of $23 \mathrm{~ms}$ was recorded by electric stimulation of 
$2.5 \mathrm{~V}$ with a pulse duration of $98 \mathrm{~ms}$. Electric pulse generator of the portable system wassupplied by two units of battery 1 with total voltage of $3 \mathrm{~V}$, however the actual voltage that shown on the computer display was $2.5 \mathrm{~V}$.

Figure 5 shows an example record of the muscle contraction profiles for jack mackerel of $19.8 \mathrm{~cm}$ FL with comparison of pulse type from (a) electric pulse generator and (b) battery system. The muscle contraction time and profile with the portable system was not different to those with the conventional setup (Fig.5a). However, the time duration by the portable system was longer than conventional set up, which pattern was square block pulse with sharp duration of $2 \mathrm{~ms}$.

The pattern of muscle contraction time was similar between electric pulse generator (Fig. $5 a)$ and battery system (Fig. 5b). The muscle contraction time from the electric generator pulse of 24.3 ms was not different with $24.0 \mathrm{~ms}$ from the battery stimulation pulse even with longer duration of $76 \mathrm{~ms}$, which was switch-on and -off manually.

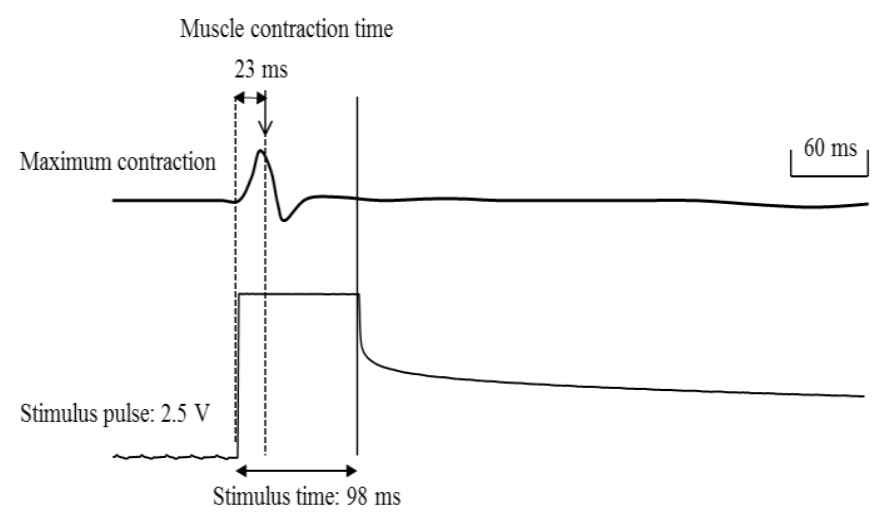

Figure. 4 Muscle contraction profile of jack mackerel recorded by portable system 

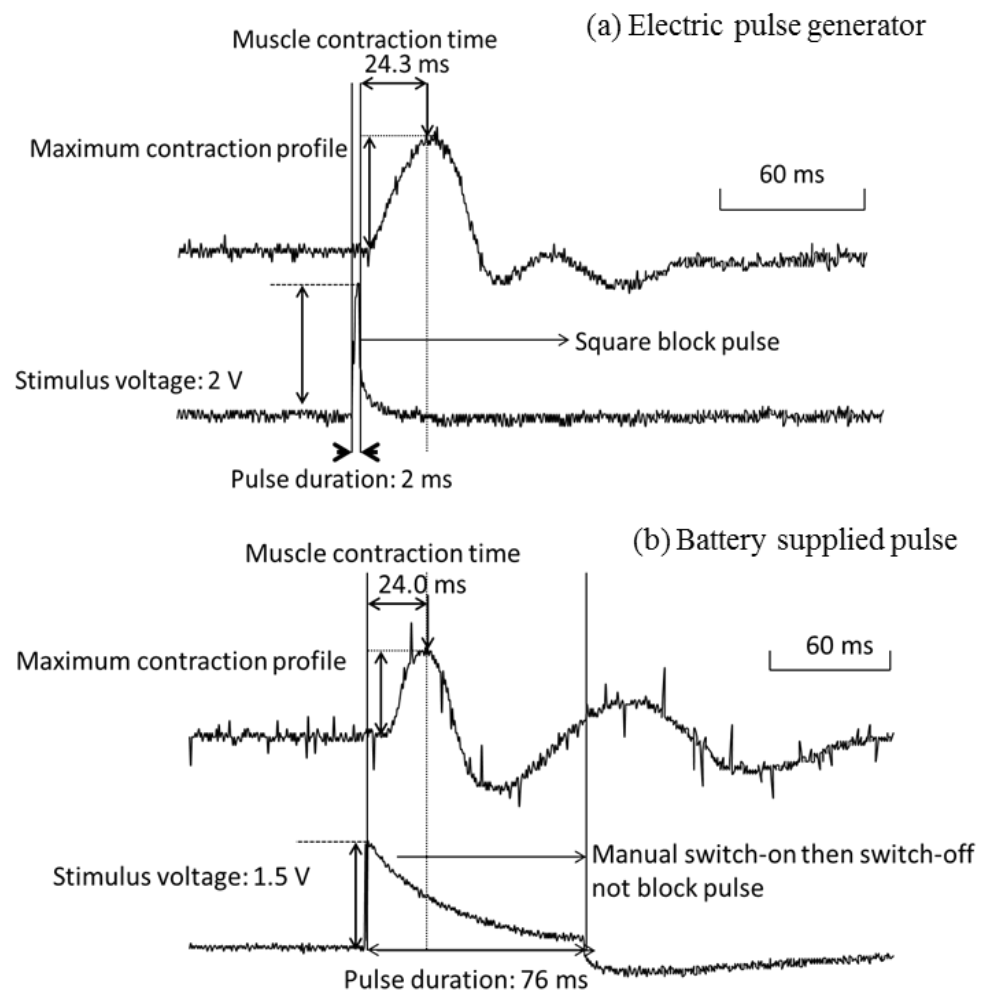

Figure 5. Muscle contraction profiles properties of jack mackerel with original setup by comparing stimulus pulse between (a) electric pulse generator and (b) battery stimulator

Figure 6 shows the muscle contraction profile with different stimulus voltages of $2 \mathrm{~V}$ and 5 $\vee$. Higher voltage is related with higher muscle contraction amplitude. The muscle contraction amplitude generated from stimulus voltage of $5 \mathrm{~V}$ as $64 \mathrm{mV}$ was higher than that of $40 \mathrm{mV}$ from stimulus voltage of $2 \mathrm{~V}$. However, the muscle contraction time just the same between two different stimulus voltages.

Muscle contraction time of jack mackerel was plotted against the longitudinal position on the lateral muscle in Fig. 7. It can be seen that the muscle contraction time was significantly longer toward the tail part (Regression analysis, $P<0.01$ ). Shortest time recorded of muscle contraction for 10 individuals of jack mackerel was obtained near the head part with the range of 19-22 ms and the longest at tail partranged as 30-41 ms (Fig 7a).Fig. $7 \mathrm{~b}$ shows that the muscle contraction time from 5 individuals was not different at each position between electric stimulator and battery (ANOVA, $P<0.01$ ) at the water temperature of $18.2^{\circ} \mathrm{C}$. Shortest recorded muscle contraction time was ranged from $20.4-25.0 \mathrm{~ms}$ and the longest as 25.2-44.8 ms. 

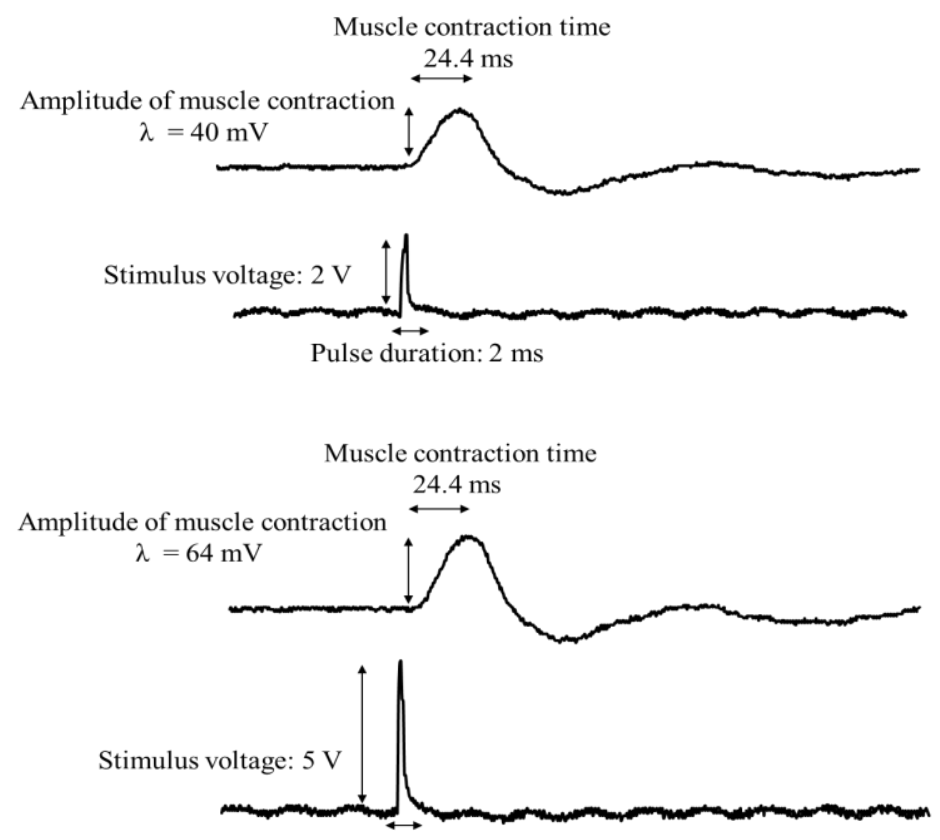

Pulse duration: $2 \mathrm{~ms}$

Figure 6. Muscle contraction profile with different stimulus voltage as $2 \mathrm{~V}$ and $5 \mathrm{~V}$, with the electric pulse generator

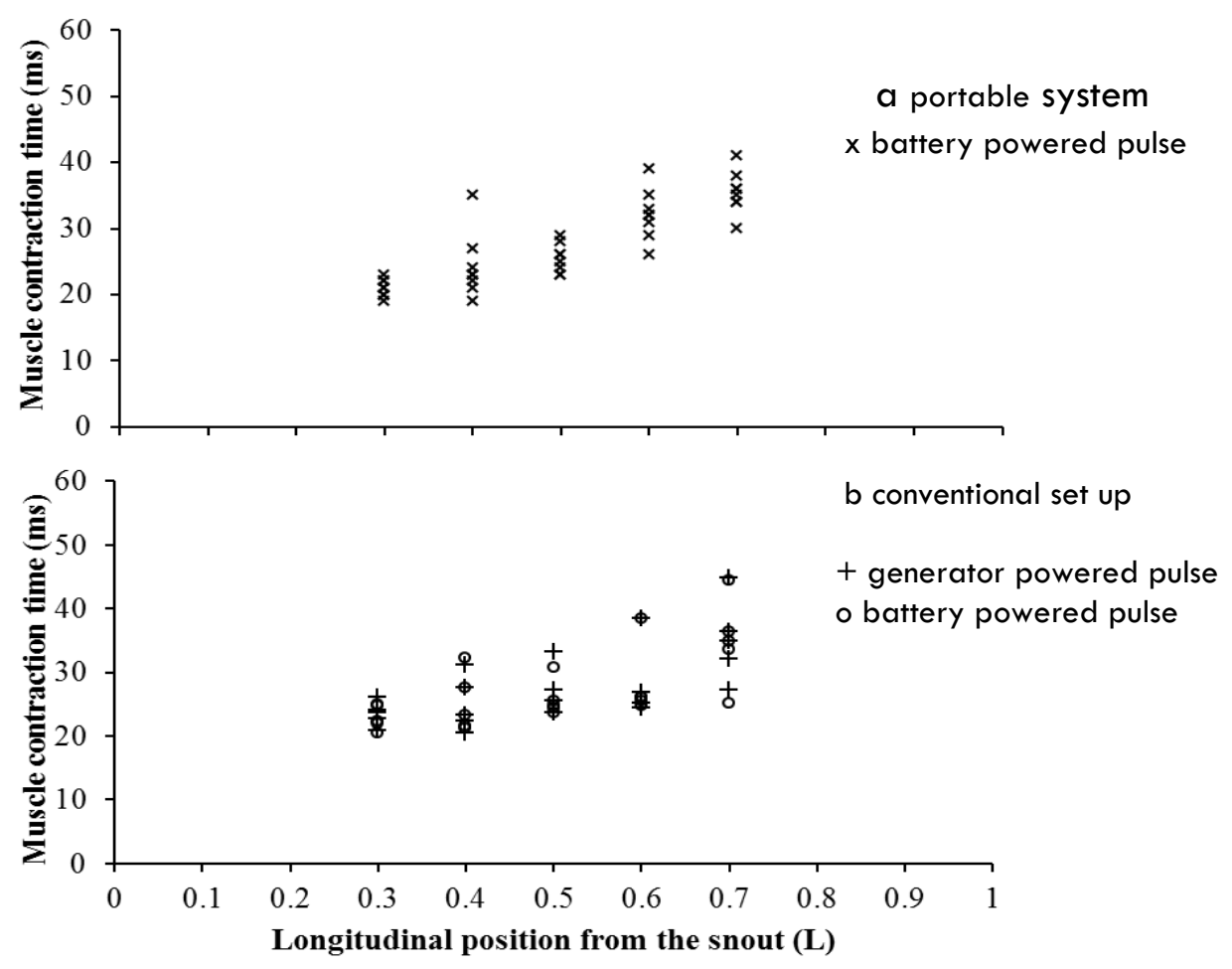

Figure 7. Muscle contraction time of jack mackerel for different position recorded by (a) portable system and (b) conventional set up with generator and battery powered pulse 
In order to compare muscle contraction time among three measurement methods, the average results were plotted according to the longitudinal position from the snout in Fig. 8 . The result indicated that the muscle contraction time was not different among the different setup systems (two-way ANOVA, $P=0.80$ ). The shortest recording of muscle contraction time near the head with the portable system was $22.6 \pm 2.1 \mathrm{~ms}$, not different to that $24.2 \pm 2.0 \mathrm{~ms}$ with the stimulus pulse generator powered by the battery system.

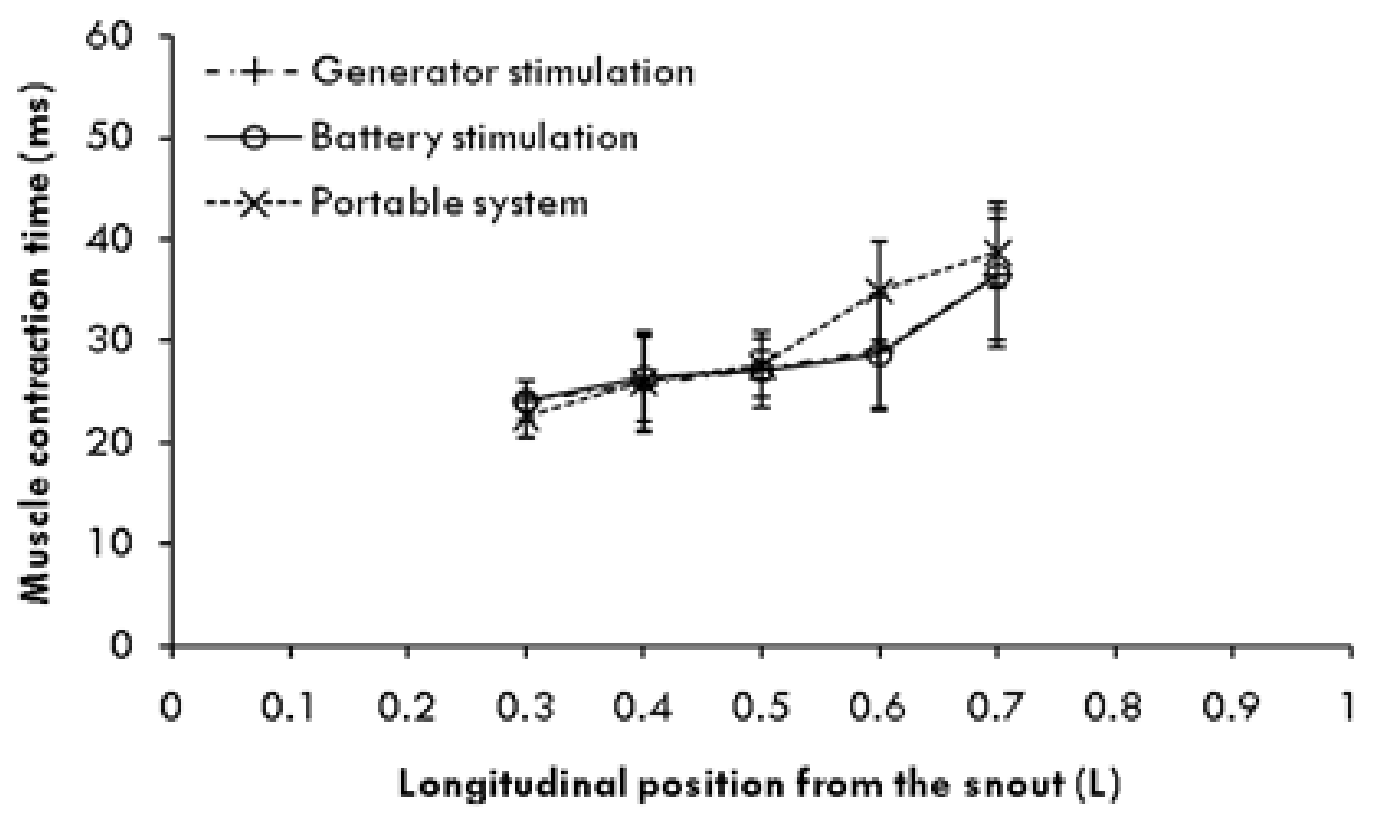

Figure 8. Average muscle contraction time, among 3 different measurement conditions

The present study demonstrates that the muscle twitch experiment of jack mackerel can be successfully measured with the portable system showing the patterns both of the muscle contraction time and electric stimulus pulse and compared with the conventional setup. Based on the muscle contraction profile of portable system (Fig. 4) and electric generator and battery system (Fig.5), we can understand that the muscle contraction profile was not changed between portable system and conventional setup, even with different patterns of the electric stimulus pulse. This resultis in a good agreement with previous study by Xu (1989). The important factor to release the muscle contraction was the initial instance of an electric stimulus given, not affected by the time duration of stimulation pulse. Moreover, the differed stimulus voltage changed the muscle contraction amplitude, however not affecting the value of muscle contraction time (Figure 6).

The results of the muscle contraction time monitored in the present study were in agreement with the previous studies, for indicating that the contraction time tended to be longer toward the tail (Yanase 2002).Wardle (1989), reported that at the maximum swimming speed of $10 \mathrm{~Hz}$ for bluefin tuna, the opposing muscles progressively overlap their contraction toward the tail, by stiffening the body. The shortest recording of muscle contraction 
time near the head part can be used to estimate the maximum tail beat frequency, and hence to estimate the maximum swimming speed (Riyanto et al. 2013).

The pattern of muscle contraction time was not different between electrical stimulation pulse and battery system. Time duration of stimulation pulse by an electric pulse generator was sharp square block and shorter than that by the battery system. The advantageof the portable system is easy to operate for recording the muscle contraction, electric pulse profiles, and directly shownin the computer display through DCS-400A software, so that we can evaluate the data to eliminate the failure patterns according to the profile patterns.

Based on these results, we concluded that the portable system with the battery pulse stimulation can be equivalent function for measuring muscle contraction time with $\mathrm{AC}$ powered conventional setup, for the field experiment in order record and quantify a reliable evaluation of the muscle activity with onboard trials. Further research of technical improvement of portable system is still needed through the development of simple battery stimulator with the highly sharp sensitivity to produce the sharp stimulating pulse similar to the electric pulse generator.

\section{REFFERENCES}

Arimoto $T, X \cup G$, Matsushita $Y$ (1993) Muscle contraction time of captured walleye pollock Theragra chalcogramma. Nippon Suisan Gakkashi 57:1225-1228

Amornpiyakrit T (2003). Study on the physilological and behavioral aspects in the capture process of trawl gear. PhD thesis. Tokyo University of Marine Science and Technology.

Brill RW, Dizon EA (1979) Effect of temperature on isotonic twitch of white muscle and predicted maximum swimming speed of skipjack tuna, Katsuwonus pelamis. Env Biol Fish 4:199-205

Johnston IA (1980) Contractile properties of fish fast muscle fibres. Mar Biol Lett 1: 323-328

He P (1986) Swimming performance of three species of marine fish and some aspects of swimming in fishing gears. PhD thesis. The University of Aberdeen

Özbilgin H, Wardle CS (2002) Effect of seasonal temperature changes on the escape behavior of haddock Melanogrammus aeglefinus, from the codend. Fish Res 58:323-331

Özbilgin $\mathrm{H}$, Pehlivan M, Basaran F (2011) Maximum swimming speed predictions for Mullus berbatus(Linnaeus, 1758) and Diplodus annularis (Linnaeus, 1758). Turk J Zool 35 (1): 79-85

Riyanto $M$, Yanase K, Arimoto $T$ (2013). Temperature and fatigue effect on the maximum swimming speed of jack mackerel Trachurus japonicus. Fish Sci DOI 10.1007/s12562013-0686-6.

Wardle CS (1975) Limit of fish swimming speed. Nature 255:725-727

Wardle CS, Videler JJ, Arimoto T, Franco JM, He P (1989). The muscle twitch and maximum swimming speed of giant bluefin tuna Thunnus thynnus L. J Fish Biol 35:129-137

X $\cup$ (1989) Study on the fish swimming movement and its application in fishing by trawl. PhD thesis. Tokyo University of Marine Science and Technology.

Yanase K, Eayrs S, Arimoto T (2007) Influence of water temperature and fish length on the maximum swimming speed of sand flathead, Platycephalus bassensis: implications for trawl selectivity. Fish Res 84:180-188 